\title{
The management of epistaxis in accident and emergency departments: a survey of current practice
}

\author{
B. KOTECHA ${ }^{1}$, R. A. COCKS ${ }^{2}$ \& M. P. ROTHERA ${ }^{3}$ \\ ${ }^{1,3}$ ENT Department and ${ }^{2}$ Accident and Emergency Department, Hope Hospital, Salford, \\ England
}

\section{SUMMARY}

A short questionnaire on the subject of the management of epistaxis was sent to forty accident \& emergency departments in two NHS regions. Thirty replies were received (response of $75 \%$ ).

It was found that all departments were involved in the initial management of epistaxis, but the extent of that involvement varied considerably. One of the most obvious factors contributing towards the degree of involvement was the liaison between the accident \& emergency and the ENT departments. Three departments never referred patients to the ENT department for follow-up.

Nine departments performed their own nasal cautery, but half of these did not use any form of local anaesthesia. Twenty-seven departments used various forms of nasal packing but, of these, two-thirds did not use any form of local anaesthesia.

Twenty-three departments allowed patients to go home with a nasal pack in situ.

The results of this survey are discussed and a guideline to the management of epistaxis in an accident $\&$ emergency setting is suggested.

\section{INTRODUCTION}

Epistaxis is a common ENT emergency which often presents first to the accident \& emergency department.

It has been reported that approximately $10 \%$ of the population have suffered a significant nose bleed at some time (Shaheen, 1967). The cause for an epistaxis can only be found in approximately $15 \%$ of patients (Juselius, 1974). The remainder are classified as idiopathic. 
Commonest identifiable causes other than trauma to exposed blood vessels are various blood dyscrasias and anti-coagulant therapy. Hereditary haemorrhagic telen $\frac{\Phi}{6}$ gectasia is a rarer identifiable cause. Much the commonest group of patients requiring hospital admission for a nose bleed are the so-called cardiovascular causes which form? about half of the entire total. Although it is commonly thought that the cause of bleeding in these patients is hypertension, careful studies (Shaheen, 1970; Weiss, 1972 have shown that blood pressure in these patients is no higher than in an age-and sex- matched controlled population. It appears that whilst hypertension may initiate the bleeding, its persistence and severity are explained not by the elevated blood pressure but by the inability of the large vessels to contract.

The management of epistaxis is traditionally divided into two phases, firstly the initial arrest of haemorrhage and secondly the identification and treatment of the underlying cause.

In this study we are concerned with current practice in the first phase.

\section{METHOD}

A questionnaire was formulated containing six questions enquiring about the curren practical management of epistaxis in the accident and emergency department. This was sent to $\mathbf{4 0}$ accident \& emergency departments in two NHS regions, marked for the attention of the Consultant in charge. A separate sheet inviting other comments vass included.

\section{RESULTS}

Thirty accident \& emergency departments responded (75\%). One of the departments had recently closed and was excluded from the analysis. All 29 remaining departments. were involved in the initial management of epistaxis.

Fourteen (48\%) dealt with less than five patients each week, 13 (45\%) dealt with 5-10. patients and two departments $(7 \%)$ dealt with 10-20 patients each week.

Three departments $(10 \%)$ said that they never referred any patients to the ENTo department for follow-up of an epistaxis. The other responses were as follows:

Fifteen departments $(52 \%)$ referred about a quarter of their patients. Six departments $(21 \%)$ referred half of their patients and five departments $(17 \%)$ referred about three-o quarters of their patients to the ENT department.

None of the departments had a policy of referring all patients with epistaxis to the ENT department.

Nine departments (31\%) performed some form of nasal cautery. Four of these never used any form of local anaesthesia prior to cautery, four used cocaine and one used lignocaine. The majority used silver nitrate sticks but one department used galvanocautery. None used trichloracetic acid.

Only three of the 29 departments were not involved in nasal packing in those patients? 
who needed it. They relied on the ENT department to perform this task. Of the 26 departments where packing was performed, 18 (69\%) did not use any form of local anaesthesia prior to insertion of nasal packs. Of the remaining eight departments, equal numbers used lignocaine and cocaine as the local agent of choice. The type of tamponade used were as illustrated in Table 1.

Table 1 Type of tamponade used

\begin{tabular}{lc}
\hline Types of pack & Number of departments \\
\hline BIPP & 23 \\
Paraffin Gauge & 2 \\
Brighton Catheter & 2 \\
Foley Catheter & 1 \\
KY Rolex Packing & 1 \\
Simpson's Balloon & 0 \\
\hline
\end{tabular}

NB: Three departments used more than one method.

Twenty-three $(88 \%)$ of the departments who inserted nasal packs allowed their patients to go home with the packs in situ. The others routinely admitted patients for observation either to an ENT or accident \& emergency short stay ward.

Twenty-two ( $84 \%$ ) of the 26 departments removed the nasal packs themselves. Three (12\%) referred the patient to the ENT department for pack removal and one department expected the GP to perform this procedure. The time of removal of pack is illustrated in Table 2.

Table 2 Removal time of nasal packs

\begin{tabular}{lc}
\hline Removal time & Number of departments \\
\hline $12 \mathrm{~h}$ & 1 \\
$24 \mathrm{~h}$ & 24 \\
$36 \mathrm{~h}$ & 1 \\
$48 \mathrm{~h}$ & 4 \\
Total & 30 \\
\hline
\end{tabular}

NB: This table includes four extra responses where a range was given, e.g. 24-36 h is included both in 24 and $36 \mathrm{~h}$.

Additional comments were made by 11 respondents which will be discussed below.

\section{DISCUSSION}

The weekly numbers of attendance with epistaxis varied considerably amongst departments. One commented that their high rate was due to a large local geriatric population. 
There were two departments that dealt with paediatric patients solely. One of thesem reported seeing less than five patients with epistaxis each week, whereas the other dealt $\stackrel{\Xi}{\oplus}$ with five to ten patients with epistaxis each week.

Cautery was performed in $31 \%$ of departments. Adequate training is necessary for the safe use of this method whatever the specific technique adopted but particularly in the case of galvanocautery. Local anaesthesia is considered essential prior to cauterization. There is a risk of septal perforation if cautery is applied to both sides of the septum.

Ninety per cent of the departments inserted nasal packs but $70 \%$ did not use local $\frac{\bar{m}}{\vec{\sigma}}$ anaesthesia prior to packing. The advantages of using local anaesthetic include better patient co-operation due to reduction in pain and more effective haemostasis (cocaine on its own effectively shrinks the congested nasal mucosa and lignocaine with adrenaline achieves the same results). It is doubtful whether an effective anterior pack can be $\vec{\omega}$ achieved without local anaesthesia and without effective tamponade, bleeding continues $\frac{\mathbb{D}}{\mathbb{D}}$ posteriorly. BIPP is the most commonly used medicated ribbon gauze for packing but $\stackrel{3}{3}$ cannot be used in patients with iodine allergy. An alternative in such cases would be to use BOPP (bismuth oxide paraffin paste).

One respondent commented that nasal packing had traditionally been performed by $\rho$ experienced nursing staff but this policy has recently been called into question. $\overrightarrow{ }$ Whoever performs the packing must be adequately trained in the techniques; the 3 question of training for both medical and nursing staff was a cause for concern $\stackrel{\rho}{\mathcal{S}}$ mentioned by other respondents.

One consultant mentioned a death which was directly attributable to a patient having \& been sent home with a nasal pack in situ. This emphasizes the importance of taking social history and that elderly patients living alone are best admitted for observation. for any reason a patient cannot be admitted for observation, the packing should not be

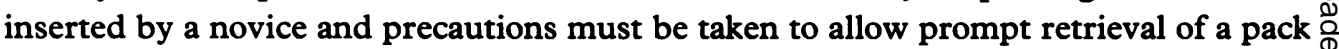
which unravels posteriorly into the airway. Bilateral packs can be tied together 2 anteriorly and unilateral packs tagged externally with a safety pin.

If nasal packs are left in situ for $\mathbf{4 8} \mathrm{h}$ or more there is a risk of infection in the paranasal sinuses developing due to blocking of the sinus ostia (Groves \& Gray, 1985). Prophylactic antibiotics should be used in such cases.

Eighty-four per cent of departments removed their own packs, the rest referring to the ENT department or, in one case, to the GP. Wherever the pack is removed, facilities for dealing with re-bleeding must be available. It is also desirable that an adequate reexamination is performed at the time of removal of nasal packs.

Two respondents said that there was no on-site ENT service but that they possessed 9 or had developed the ENT experience needed to fill the gap. Two other respondents complained of poor relationship with their ENT departments but another said that an ENT clinic was held each weekday in the accident \& emergency department. Two departments commented on the junior doctors feeling unsure about the management of $N$ epistaxis and one complained of the lack of teaching available.

Some of the comments received serve to highlight the need for closer liaison between $\bar{O}$ the specialities of accident \& emergency and otolaryngology. Some accident \& emergency consultants clearly have a special interest in ENT emergencies and could teach their junior staff in the practical setting. However, in most departments much could be 
gained by involving the ENT staff in practical and theoretical teaching for each new intake of SHOs.

Our guidelines for the management of epistaxis in an accident \& emergency setting are suggested below in seven simple steps:

(1) Assessment of patient's cardiovascular status and commencement of appropriate resuscitative measures.

(2) Application of local anaesthetic agent in the form of a spray-either $5 \%$ cocaine or $4 \%$ lignocaine + adrenaline.

(3) Examination of the patient's nasal cavity using adequate illumination and suction apparatus to remove blood clots.

(4) Cauterization of any obvious bleeding points using silver nitrate sticks for $20 \mathrm{~s}$.

(5) If bleeding not settled, then insertion of well secured anterior nasal pack using BIPP.

(6) If bleeding settled then decide cautiously whether to admit patient for observation or to send patient home with packs in situ.

(7) If bleeding still not settled, referral of the patient to ENT department for further management.

\section{ACKNOWLEDGEMENTS}

The authors would like to thank all the consultants who helped our survey by completing and promptly returning the questionnaire.

\section{REFERENCES}

Groves J., \& Gray R. F. (1985) A Synopsis of Otolaryngology. John Wright, Bristol p 226-30

Juselius H. (1974) Epistaxis. fournal of Laryngology and Otology 88, 317.

Shaheen O. H. (1967) MS Thesis Epistaxis, University of London.

Shaheen O. H. (1970) Studies of nasal vasculature and problems of arterial ligation for epistaxis. Of Royal College of Surgeons of England 47, 30.

Weiss N. S. (1972) The relation of high blood pressure to headache and epistaxis and selected other symptoms. New England fournal of Medicine 287, 631.

\section{APPENDIX 1}

Questionnaire-epistaxis in A\&E department

In the following questions more than one response may be selected. Please tick the appropriate boxes.

(1) Epistaxis attending your dept is:

Managed by $A \& E$ staff

Referred to ENT dept 
(2) In a week, roughly how many patients would attend the department with epistaxis?

a) Less than 5

b) Between 5-10

c) Between 10-20

d) More than 20

If answer is (d) please state approximate number.

(3) Roughly, what percentage of the patients attending the A\&E department with epistaxis would be referred to the ENT department?
a) None
b) About $25 \%$
c) About $50 \%$
d) About $75 \%$
e) All

(4) Is cauterization used in your department:

If Yes:

(a) Type of anaesthetic used prior to cautery:
(i) None
(ii) Lignocaine
(iii) Cocaine
(iv) Other

(b) Method of cautery:

$\mathrm{Agno}_{3}$ Sticks

Trichloracetic Acid

Galvanocautery

Other

(5) Is nasal packing performed in the department:

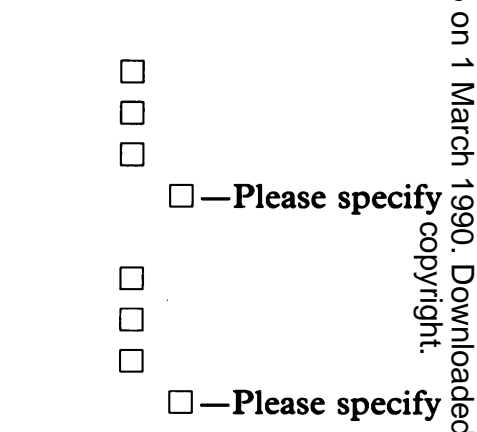

If Yes:

Yes $\square$

No

(a) Type of local anaesthetic applied prior to packing:
(i) None
(ii) Lignocaine
(iii) Cocaine
(iv) Other

(b) Type of packs used:
(i) BIPP
(ii) Simpson's Balloon
(iii) Brighton Epistaxis Catheter
(iv) Foley Catheter
(v) Other

(c) If after simple packing of the nose the bleeding settles, is the patientr allowed to go home with pack in situ: 
If Yes are the packs removed by:

A\&E department

ENT department

(6) If the packs are to be removed in $A \& E$ department, does the patient return for this to be done in:

$12 \mathrm{~h} \square$

$24 \mathrm{~h}$

$36 \mathrm{~h}$

$48 \mathrm{~h}$

(7) Other comments regarding epistaxis in A\&E setting if any: 